\title{
EVENTO DE PRECIPITAÇÃO INTENSA OCORRIDO NOS DIAS 15 E 16 DE ABRIL DE 2018 EM FORTALEZA-CE: ESTUDO DE CASO
}

\author{
MORAES, Dayse - dayse.moraes@funceme.br \\ Fundação Cearense de Meteorologia e Recursos Hídricos/Funceme \\ COUTINHO, Maytê - mayte.coutinho@funceme.br \\ Fundação Cearense de Meteorologia e Recursos Hídricos/Funceme
}

\begin{abstract}
RESUMO: As chuvas intensas que ocorreram na cidade de Fortaleza-CE no dia 16 de abril de 2018 provocaram grandes transtornos à sociedade. Este evento associou-se a um Sistema Convectivo de Mesoescala (SCM), que se propagou entre os estados da Paraíba e do Rio Grande do Norte, induzindo grandes volumes de precipitação na cidade de Fortaleza, com acumulado diário em torno de $90 \mathrm{~mm}$, o qual influenciou significativamente no comportamento diurno das variáveis meteorológicas locais (temperatura, umidade e precipitação) e ocasionou grandes transtornos tanto para a cidade como principalmente para a população urbana, interferindo sobremaneira nas suas atividades essenciais, principalmente entre 07:00UTC e 12:00UTC, período de máxima intensidade. Os resultados mostraram que os impactos da intensa precipitação e a formação do SCM apresentaram relação direta com as águas mais aquecidas próximo à costa norte do NEB o que favoreceu a formação e o desenvolvimento circular do sistema.
\end{abstract}

PALAVRAS-CHAVES: Sistema convectivo de mesoescala; Tempestades severas; Transtorno.

EVENT OF INTENSE PRECIPITATION OCCURRED ON DAYS 15 AND 16 APRIL 2018 IN FORTALEZA-CE: CASE STUDY

ABSTRACT: The intense rains that arose in the city of Fortaleza-CE on April 16, 2018 caused great disruption to society. This event was associated to a Mesoscale Convective System (SCM), which spread between the states of Paraíba and Rio Grande do Norte, inducing large volumes of history in the city of Fortaleza, with the cumulative daily The influential diversity in the temp of these local meteorological climate (temperature, humidity and precipitation) and occasion the large activities are to the city made to the urban population, interfering its main activities, mainly between 07: 00UTC and 12: OOUTC, period of maximum intensity. The results were those that occurred in an intense and growing way in SCM over time, with the aim of improving the formation and the circular development of the system.

KEYWORDS: Mesoscale convective system; Severe storms; Disorder.

\section{EVENTO DE PRECIPITACIÓN INTENSA OCURRIDO EN LOS DÍAS 15 Y 16 DE ABRIL DE 2018 EN FORTALEZA-CE: ESTUDIO DE CASO}

RESUMEN: Las lluvias intensas que ocurrieron en la ciudad de Fortaleza-CE el 16 de abril de 2018 provocaron grandes trastornos a la sociedad. Este evento se asoció a un Sistema Convectivo de Mesoescala (SCM), que se propagó entre los estados de Paraíba y de Rio Grande do Norte, induciendo grandes volúmenes de precipitación en la ciudad de Fortaleza, con acumulado diario en torno a $90 \mathrm{~mm}$, que influenció significativamente en el comportamiento diurno de las variables meteorológicas locales (temperatura, humedad y precipitación) y ocasionó grandes trastornos tanto para la ciudad como principalmente para la población urbana, interfiriendo sobremanera en sus actividades esenciales, principalmente entre 07: 00UTC y 12: 00UTC, período de máxima intensidad. Los resultados mostraron que los impactos de la intensa precipitación y la formación del SCM presentaron relación directa con las aguas más calientes cerca de la costa norte del NEB que favoreció la formación y el desarrollo circular del sistema.

PALABRAS-CLAVE: Sistema convectivo de mesoescala; Tempestades severas; Trastorno. 


\section{INTRODUÇÃO}

As inundações e os deslizamentos são desastres naturais que ocorrem em períodos chuvosos intensos e que ganham maior destaque na mídia eletrônica e imprensa, devido aos impactos socioambientais ocasionados nas grandes áreas urbanas, como: elevado número de mortes, feridos e desabrigados; proliferação de doenças; perdas econômicas e impactos ambientais (MONTEIRO e ZANELLA, 2013).

Tais impactos estão fortemente relacionados ao fenômeno de urbanização desordenada presente nas grandes cidades brasileiras (caso de Fortaleza-CE), contribuindo nos impactos ocasionados por episódios pluviométricos extremos, os quais atingem, principalmente, as populações mais vulneráveis. Ressaltando que as chuvas só podem ser consideradas intensas em áreas urbanas a partir de $30 \mathrm{~mm} / \mathrm{h}$ e críticas quando ultrapassam $50 \mathrm{~mm} / \mathrm{h}$ (CONTI, 2011), causando verdadeiros traumas ambientais, uma vez que a capacidade dos canais do sistema hidrográfico é insuficiente para conduzir as águas, causando transbordamento em áreas densamente ocupadas (MONTEIRO e ZANELLA, 2013), como é o caso de Fortaleza, sendo que a cidade não possui infraestrutura adequada.

No início da manhã do dia 16 de abril de 2018, Fortaleza-CE sofreu grandes prejuízos ocasionados pela intensa precipitação e fortes ventos associados à formação de um Sistema Convectivo de Mesoescala (SCM). Os SCM estudados em todo o mundo (MADDOX, 1980; VELASCO e FRITSCH, 1987; VITORINO et al., 1997; SALIO et al., 2007) possuem organização própria, intensa atividade convectiva, preferências por algumas regiões e horários, e apresentam-se como uma única célula nebulosa isolada com forma arredondada, o que permite sua fácil identificação a partir de imagens de satélite, e quando o mesmo obedece à classificação espaço temporal e de intensidade feita por Maddox (1980), é chamado de Complexo Convectivo de Mesoescala (CCM). Estes sistemas tropicais possuem tempo de vida menor do que 9 horas, tamanho menor do que $150.000 \mathrm{~km} 2$ no período de máxima extensão e são mais frequentes no verão seguido do outono (SALIO et al., 2007; MORAES, 2017).

Os estágios desse sistema podem ser divididos em: gênese, estágio maduro e dissipação. A gênese ocorre geralmente no final da tarde e início da noite, quando as primeiras células convectivas se desenvolvem em uma região com condições favoráveis à convecção. Durante o período da noite, horário em que a atmosfera em baixos níveis encontra-se mais estável, o fluxo de calor e umidade proveniente da região amazônica passa a fornecer condições necessárias para que esses sistemas cresçam. O estágio maduro geralmente ocorre durante a madrugada, coincidindo com o horário de máxima intensidade do Jato de Baixos Níveis (JBN). Nessa etapa, tempestades severas podem ainda ocorrer; entretanto, o tipo principal de condições do tempo passa a serem fortes chuvas localizadas. Durante o estágio de dissipação (por volta das 1200 UTC), o fluxo de calor e de umidade é reduzido em razão do aumento dos processos turbulentos que atuam para desacelerar o escoamento de norte canalizado pelos Andes, interrompendo ou modificando o suprimento de combustível para o sistema (SILVA DIAS et al., 2009).

Além dos SCM, vários são os sistemas atmosféricos que atuam no tempo e no clima em Fortaleza-CE, sendo o de maior importância a Zona de 
Convergência Intertropical-ZCIT, responsável por induzir chuvas no Ceará geralmente no período de fevereiro a maio (quadra chuvosa)(Moura; Shukla, 1981; Wang, 2002). De acordo com Zanella (2006), outros sistemas também podem ser importantes na ocorrência de chuvas para a cidade. São eles: os Vórtices Ciclônicos de Altos Níveis (VCAN), responsáveis por chuvas na préestação chuvosa, se estendendo até março; as linhas de instabilidade (LI), que geram chuvas principalmente em fevereiro e março; o sistema de brisas que ocasionam chuvas na área costeira e após a quadra chuvosa, prevalece principalmente a atuação dos distúrbios ondulatórios de leste (DOL) entre junho e agosto (MOTA, 1997; COUTINHO; FISH, 2007).

Na porção Norte do Nordeste do Brasil (onde está inserida a Região Metropolitana de Fortaleza-CE (RMF) a ocorrência dos SCM se dá com maior frequência nos meses de março e abril. Um exemplo típico é relatado em Souza et al. (1998), onde ocorreram chuvas sobre a cidade, no dia 24/04/97, durante 13 horas seguidas (entre 01:00h e 13:00h local). Ao final desse período havia chovido $270 \mathrm{~mm}$, correspondendo a $79 \%$ da climatologia do mês de abril, para o posto pluviométrico da Fundação Cearense de Meteorologia e Recursos Hídricos - FUNCEME. Segundo Hastenrath e Heller (1977) e Souza et al. (2000) esses meses são os de maior concentração das chuvas dentro da quadra chuvosa (fevereiro a maio) nessa região.

No dia 16 de abril de 2018 , os jornais noticiaram muitos problemas à população, entre eles, cita-se (Jornal Diário do Nordeste): houve alagamentos e transtornos em diversos bairros e moradores relataram pequenas explosões na fiação elétrica, a chuva nesse dia teve duração de 10 horas seguidas.

Com isso, o presente trabalho objetiva realizar uma análise sinótica da evolução temporal, do ciclo de vida e das condições meteorológicas relacionadas à atuação de um SCM observado no litoral fortalezense e impacto associado.

\section{MATERIAL E MÉTODOS}

\section{REGIÃO DE ESTUDO}

Localizada na faixa central da zona litorânea do estado do Ceará, a cidade de Fortaleza, situa-se no setor norte da região Nordeste do Brasil (NEB), com as seguintes coordenadas geográficas: $3^{\circ} 45^{\prime} 47^{\prime \prime} \mathrm{S}$ e $38^{\circ} 37^{\prime} 35^{\prime \prime} \mathrm{W}$, e tem como limites o oceano Atlântico a norte e nordeste, Rio Grande do Norte e Paraíba a leste e Piauí a oeste. O clima da região é predominantemente semiárido, com média anual de temperatura do ar em torno de $30,8^{\circ} \mathrm{C}$ e a pluviosidade média anual é 1444,6mm (FUNCEME, 2010). 


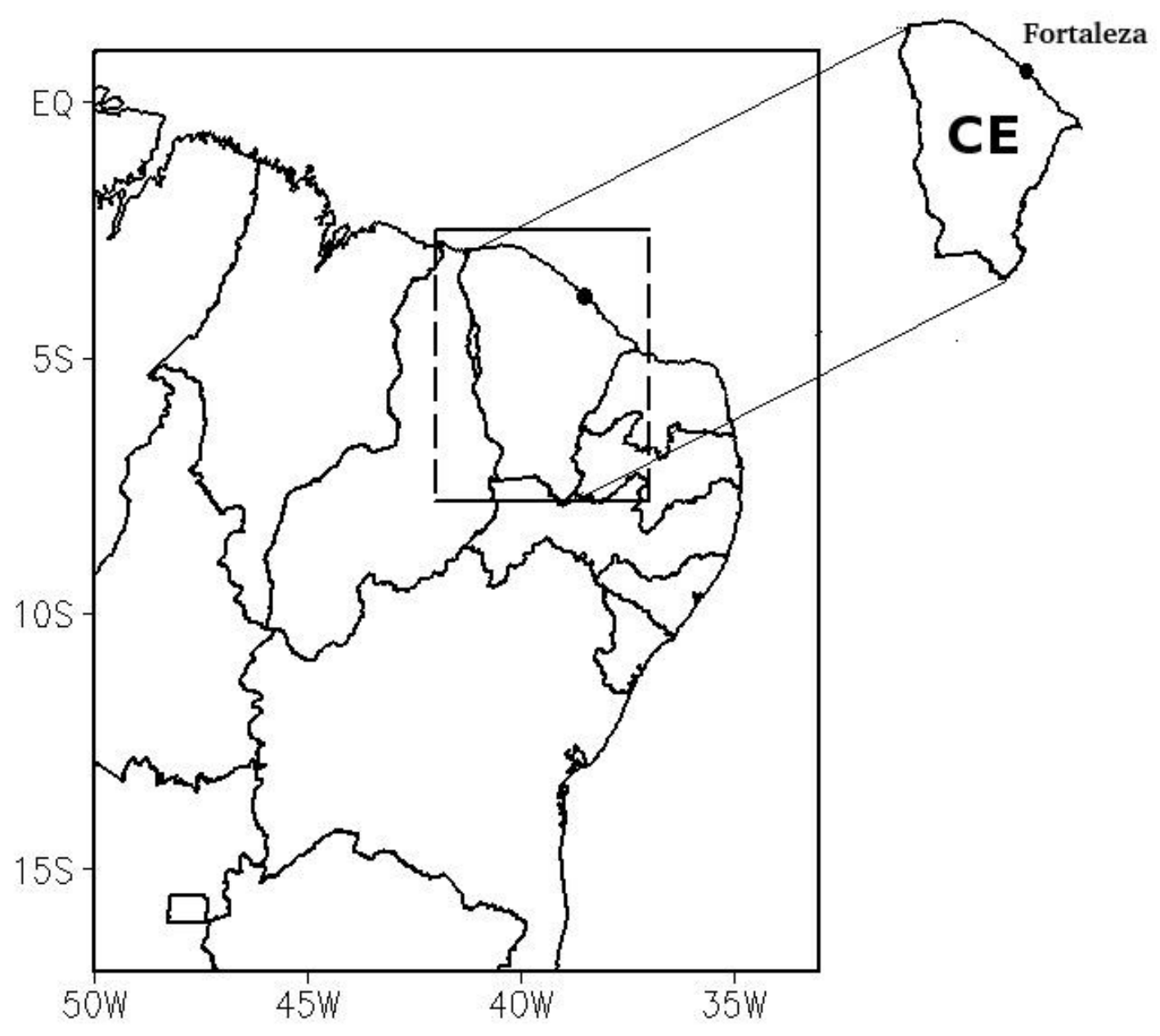

Figura 1 - Localização da área de estudo. Fonte: As autoras.

\section{DADOS}

\section{IMAGEM DE SATÉLITE}

Neste trabalho utilizaram-se as imagens horárias do satélite GOES-16 canal de temperatura do topo de nuvens, processadas pelo Centro de Previsão do Tempo e Estudos Climáticos (CPTEC) entre os dias 15 e 16 de abril de 2018, para melhor analisar as células convectivas profundas. Neste estudo, utilizaramse as imagens apenas como ilustrações.

\section{PRECIPITAÇÃO}

Nesta pesquisa, utilizaram-se dois conjuntos de dados a fim de comparar a estimativa de precipitação do MERGE (técnica baseada na combinação de dados observacionais das estações de superfície com as medidas em microondas dos satélites TRMM-Tropical Rainfall Measuring Mission) com valores observados (pluviômetros) pela FUNCEME. 


\section{OBSERVADA}

Os totais acumulados da precipitação observada no estado do Ceará, no dia 16 de abril de 2018, obteve-se da rede pluviométrica gerenciada pela FUNCEME. Foram observações feitas de 7h do dia 15 de abril as 7h do 16 de abril de 2018, de um total de 550 pluviômetros. Desses, em Fortaleza (área de estudo) são 4 postos no total, sendo eles: Posto do Pici, da Água fria, da Messejana e do Castelão .

\section{ESTIMATIVA DE PRECIPITAÇÃO (MERGE)}

O MERGE é uma técnica que visa combinar as estimativas de precipitação por satélite TRMM, para verificar a precipitação associada aos sistemas convectivos, com observações de superfície (Surface Synoptic Observations SYNOP) sobre o continente da América do Sul (VILA, 2008; VILA et al. 2009). Os campos de precipitação foram gerados a partir da composição de dados do SYNOP obtidos do Instituto Nacional de Meteorologia (INMET), plataforma automática de coleta de dados (PCD) do Sistema Brasileiro de coleta de dados via Satélite do Instituto Nacional de Pesquisas Espaciais (INPE), e de pluviômetro convencionais fornecidos pelo programa de Monitoramento de Tempo Clima e Recursos Hídricos (PMTCRH) do Ministério de Ciência e Tecnologia (MTC) (ROZANTE et al. 2010).

\section{REANÁLISE}

Foram utilizados dados diários das reanálises do NCEP/NCAR (National Centers for Environmental Prediction) que tem resolução espacial de $2.5^{\circ} \times 2.5^{\circ}$ (equivalente a aproximadamente 144 por $73 \mathrm{~km}$ ) em 17 níveis de pressão. A partir desses dados foi possível elaborar os mapas dos campos de vorticidade e linhas de correntes, ômega e divergência do vento.

\section{TEMPERATURA DA SUPERFÍCIE DO MAR}

A temperatura da superfície do mar (TSM) semanal de 16 a 22 de abril de 2018 foi fornecida pelo Instituto Nacional de Meteorologia (INMET). A partir de observações detalhadas dos dados, analisou-se a evolução temporal, o ciclo de vida e as condições meteorológicas na superfície e em altitude sobre a região de atuação do SCM observado no dia 16/04/18. Utilizou-se a TSM para verificar se teria gatilho para possível disparo de convecção na região de estudo.

\section{RESULTADOS E DISCUSSÃO IMAGEM DE SATÉLITE}

A figura 2 mostra a sequência do ciclo de vida do SCM através das imagens do satélite meteorológico GOES-16, no canal de temperatura de topo de nuvens. Entre os dias 15 e 16 de abril de 2018, é possível acompanhar a distribuição espacial da precipitação acumulada, desde a sua formação, por volta das $23 \mathrm{~h} 00 \mathrm{~min}$, até sua dissipação as $10 \mathrm{~h} 00 \mathrm{~min}$ local, com máximo de precipitação em Fortaleza de $90 \mathrm{~mm}$. Observa-se que o SCM atingiu Fortaleza, 
vindo do leste do Nordeste, nas primeiras horas da manhã, indicando que se formou na madrugada assim como citado por Velasco e Fritsch (1987), e que permaneceu ao longo do dia.

Nos horários das 04h00min às 08h00min, vê-se a formação de nuvens rasas e profundas no litoral do Ceará, onde se conclui que o SCM instabilizou a atmosfera, variando de intensidade e consequentemente de precipitação na região onde se encontram os municípios de Aratuba, Paracuru, Eusébio e principalmente Fortaleza. Com o passar do tempo, a atividade convectiva começa a desenvolver-se e progride dando forma ao SCM, com suas células convectivas assumindo a forma circular (0300 UTC). Nas imagens das (0600, 0700, 0800 UTC) do dia 16 de abril 2018, observa-se a intensificação do SCM, quando as temperaturas no topo das nuvens chegam a atingir $-65^{\circ} \mathrm{C}$. Durante 0 ciclo de vida, o SCM apresentou deslocamento para noroeste, mantendo a forma circular e por volta das $10 \mathrm{~h} 00 \mathrm{~min}$ local, do dia 16, ocorre o processo de dissipação, totalizando um ciclo de vida de aproximadamente 12 horas. Esse tempo de vida em torno de 10 horas também foi encontrado por Souza e Alves (1998), que analisaram a atuação de um SCM sobre Fortaleza-CE. 


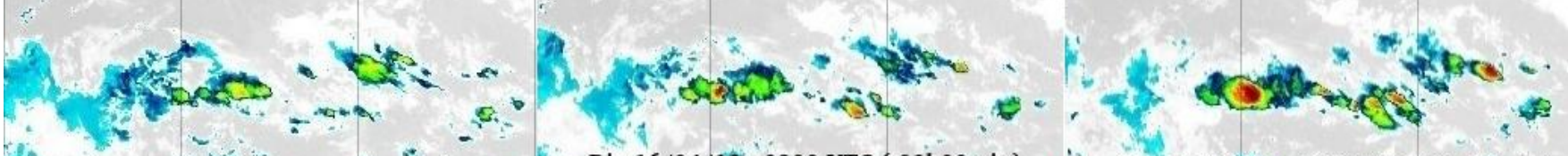

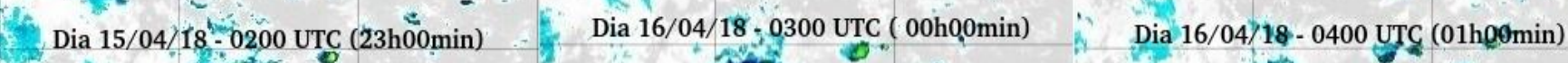

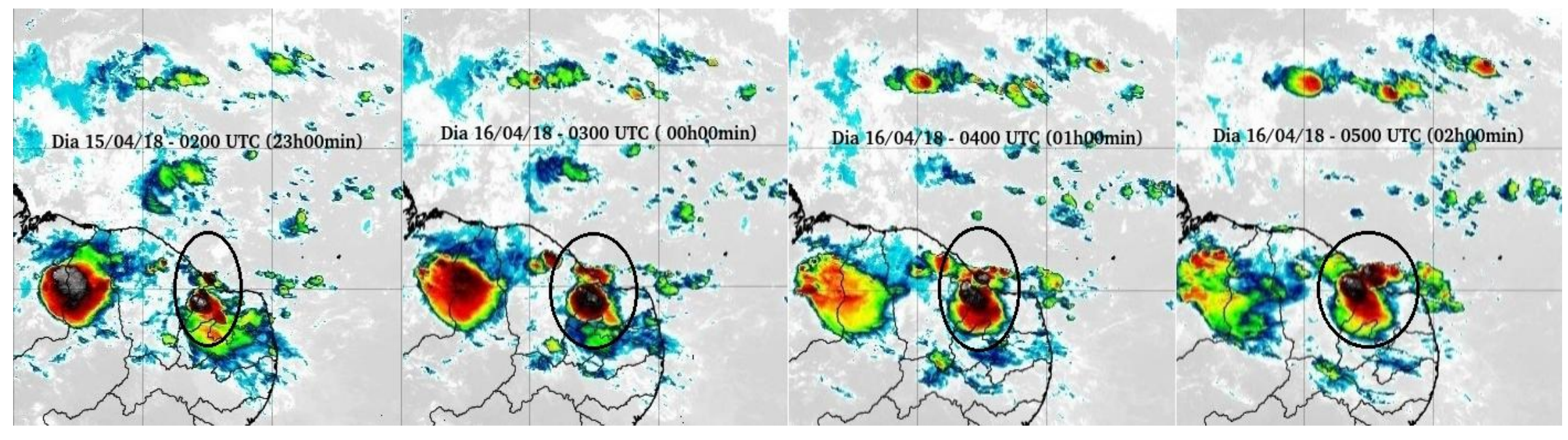

A

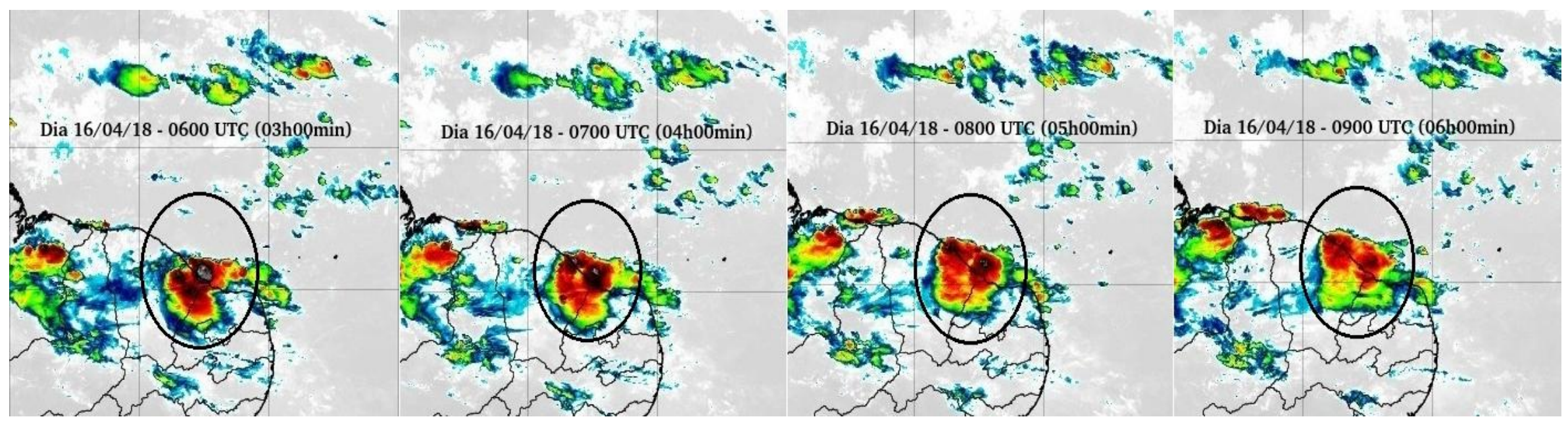



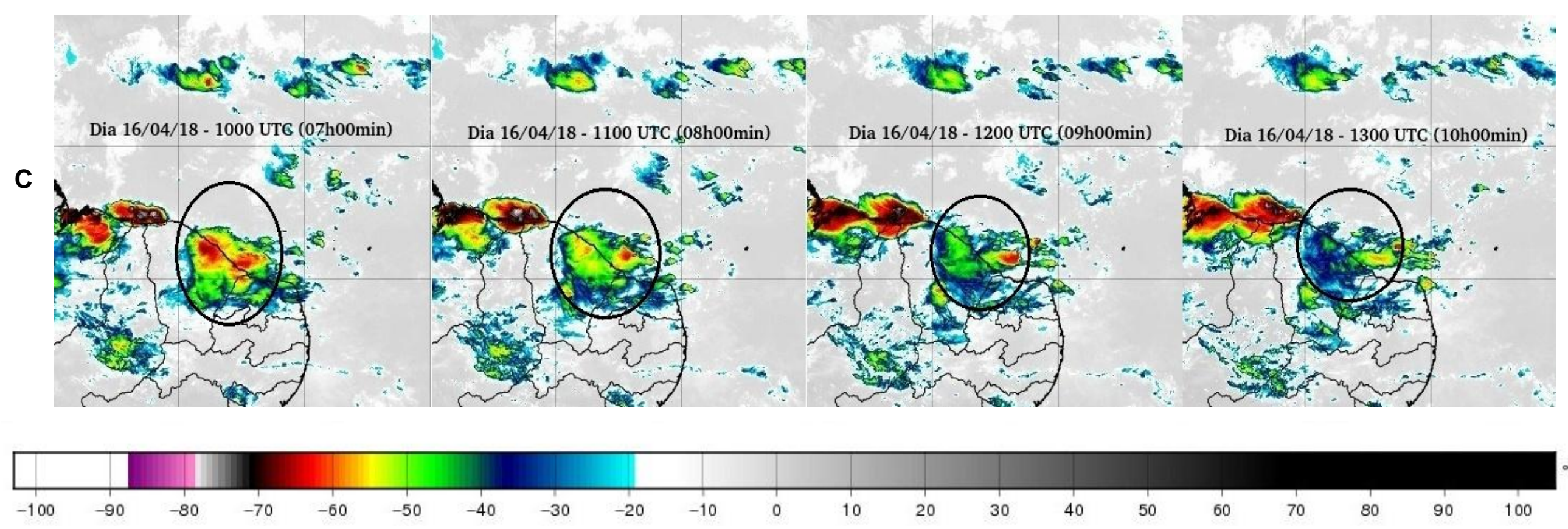

Figura 2 - Imagens do satélite GOES-16, no canal topo de nuvens e realçadas, para o Ceará do dia 16/04/2018 às 02, 03, 04, 05, 06, 07, 08, 09, 10, 11,12 e 12 UTC. (A) Gênese do sistema. (B) Estágio maduro do sistema. (C) Dissipação do sistema. Fonte: CPTEC/INPE/DSA. 


\section{PRECIPITAÇÃo}

Mostra-se na Figura 3a a distribuição espacial da precipitação acumulada observada no dia 16 de abril de 2018 sobre o Ceará, onde a RMF registrou um total de $182,5 \mathrm{~mm}$ no final desse período, o qual correspondeu a aproximadamente $51 \%$ da climatologia mensal de abril sobre a estação meteorológica da FUNCEME em Fortaleza (observações feitas das 7h da manhã do dia 15 de abril às 7h do dia 16 abril de 2018).

Ao analisarmos a precipitação acumulada estimada pelo produto MERGE (Figura 3b), nota-se que os maiores acumulados concentram-se sobre o norte do Ceará. Durante o período de atuação do SCM, foi observada na RMF, chuvas fortes, com acumulados superiores a $80 \mathrm{~mm}$, coincidentemente com o período de intensificação do SCM, nas primeiras horas da manhã, e também é possível observar na figura acumulados superiores a $60 \mathrm{~mm}$ nas regiões em que o SCM se deslocou.
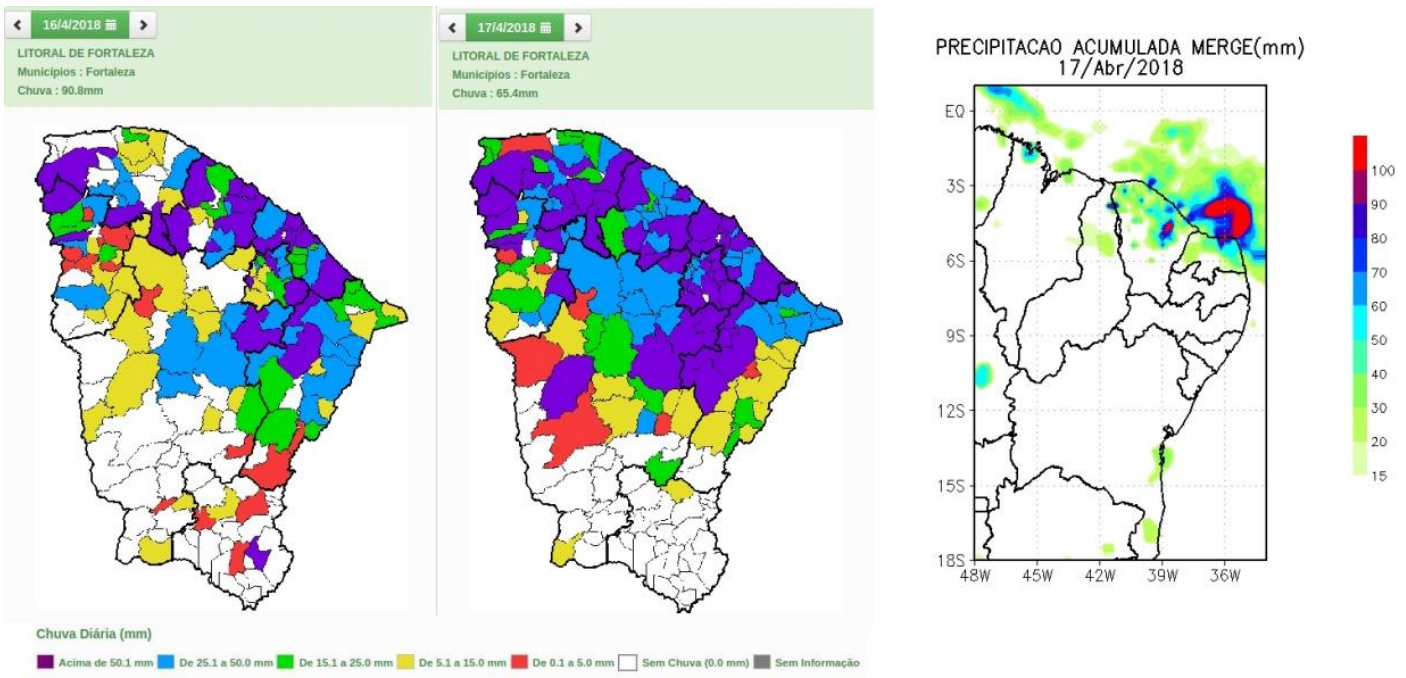

Figura 3 - Distribuição espacial da precipitação acumulada pelo MERGE e observada pela FUNCEME, sobre o Ceará, dos dias 16 e 17 de abril 2018. Fonte: FUNCEME e MERGE.

A Figura 4 mostra os campos meteorológicos observados em $850 \mathrm{hPa}$ (A), $700 \mathrm{hPa}$ (B) e $200 \mathrm{hPa}$ (C) de vorticidade e linhas de correntes, de divergência do vento e de ômega. Em 850 hPa (A), no dia 16 de abril de 2018, às 09h00min local (1200 UTC), observa-se a presença da confluência dos ventos alísios, predominante de sudeste, inclinada sobre o estado do Ceará (Figura 4A), e próximo ao litoral do estado do Maranhão e do litoral Norte do Ceará. E interessante notar a presença de um cavado invertido, associando-se com a vorticidade negativa, divergência negativa e movimento vertical ascendente (ômega negativo), indicando a presença de vorticidade ciclônica (formação de nuvens convectivas) provável responsável pela forma circular do SCM.

Com relação aos campos em altitude, mostrados na Figura 4B, observados no nível de $700 \mathrm{hPa}$, o vento apresenta-se zonal sobre o Ceará, a vorticidade positiva, o que indica circulação anticiclônica. O campo de ômega, nesse nível, começa a enfraquecer e a divergência torna-se positiva. Dessa maneira, o sistema, não tem uma área favorável para se desenvolver. 
Na Figura 4C observa-se nos níveis 200 hPa que houve predomínio de circulação anticiclônica (vorticidade positiva). Ressalta-se (1200 UTC do dia 16/04/18), período de início da dissipação do SCM, o predomínio de convergência e movimento vertical ascendente na alta troposfera (200 hPa). Por outro lado, nessa fase de dissipação do sistema, após as 1200 UTC do dia 16/04/18, houve predominância de divergência positiva nos médios e altos níveis da atmosfera.

Na Figura 5 observa-se a TSM maior do que $28^{\circ} \mathrm{C}$ na costa leste do NEB, indicando condições atmosféricas mais instáveis e consequentemente o disparo da atividade convectiva profunda. 
Vorticidade com Linhos de Corrente NCEP/NCAR (m/s)
$850 \mathrm{hPa} 16 / \mathrm{Abril} / 2018$ [12UTC]

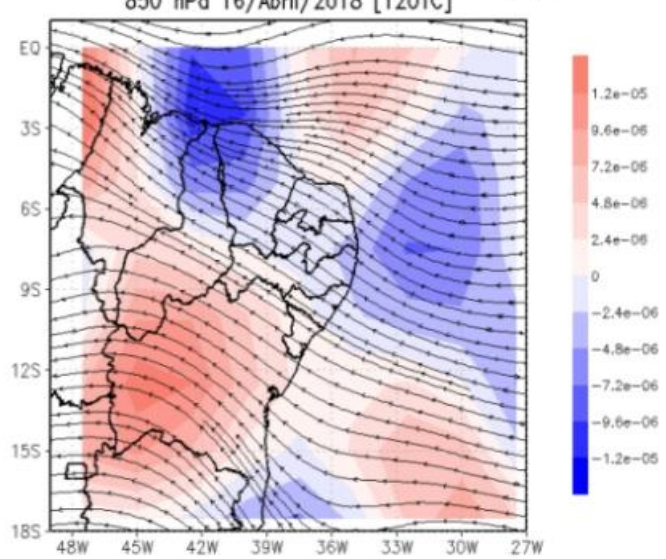

Vorticidade com Linhos de Corrente NCEP/NCAR (m/s)

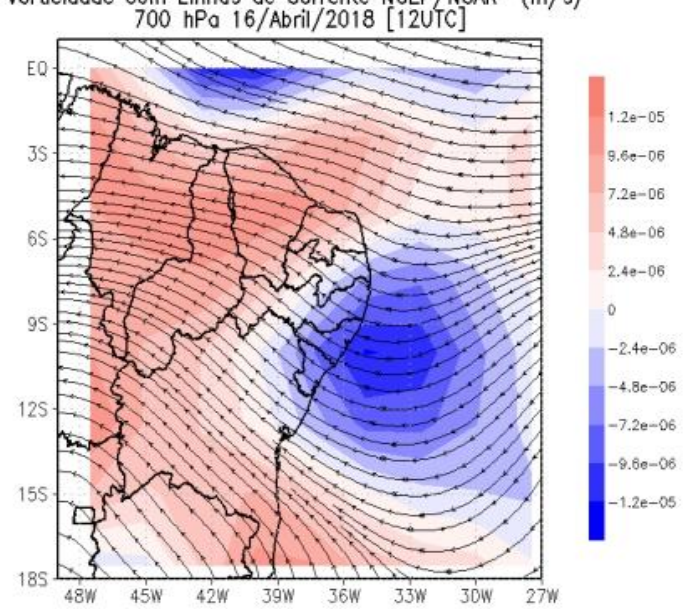

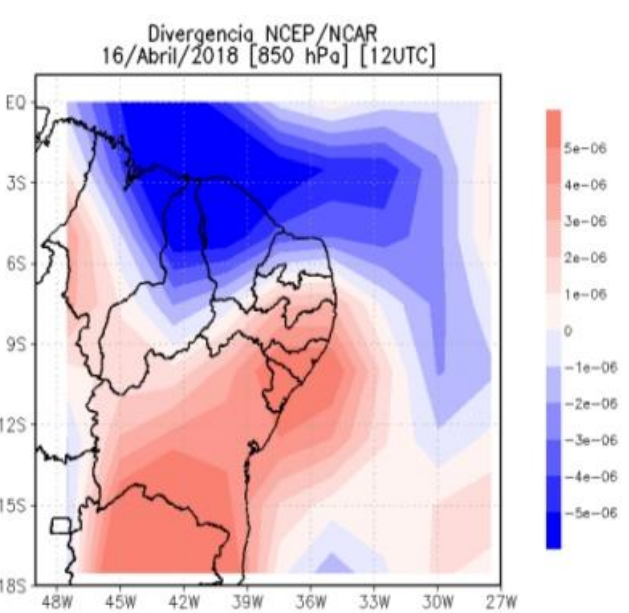
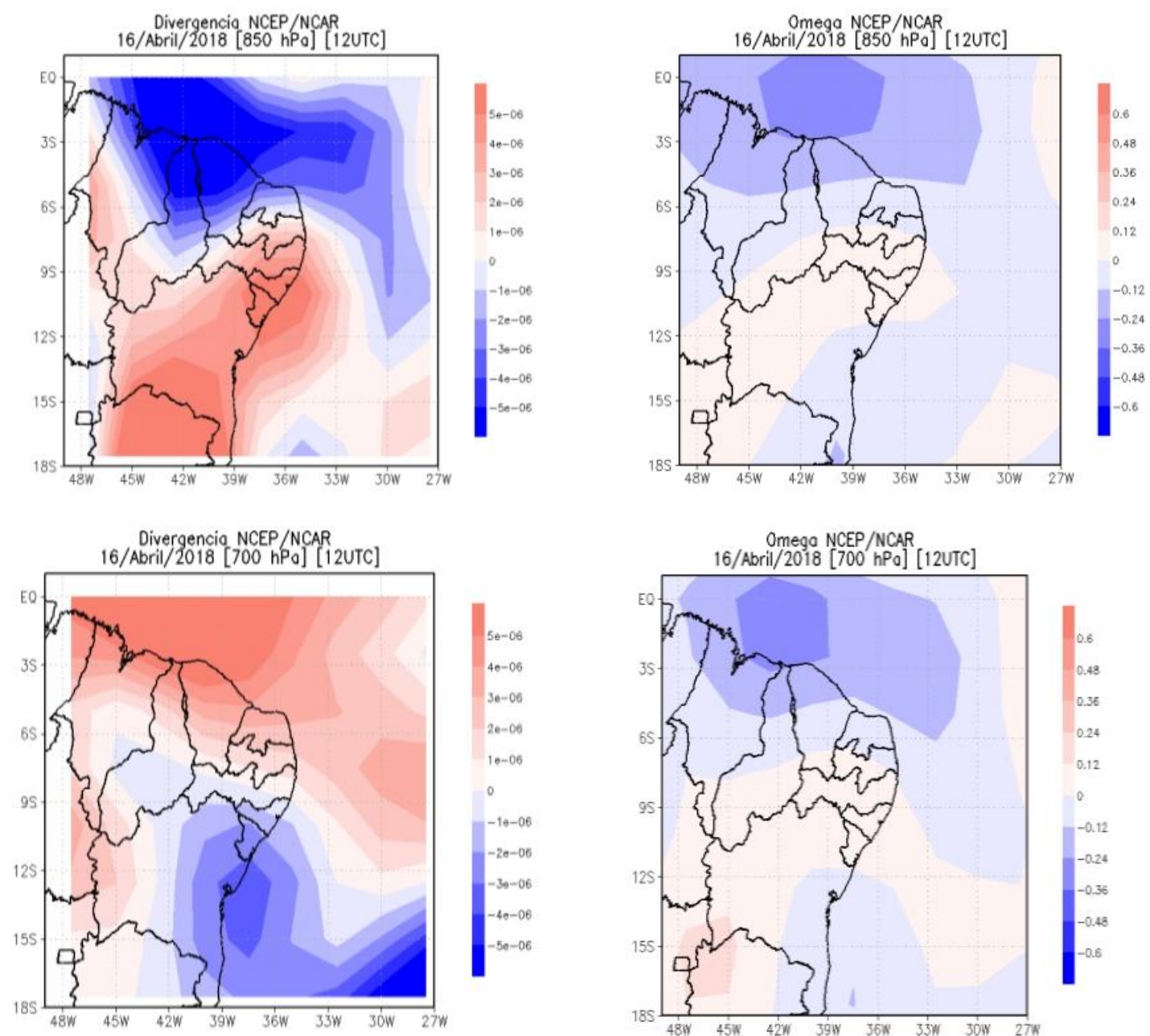

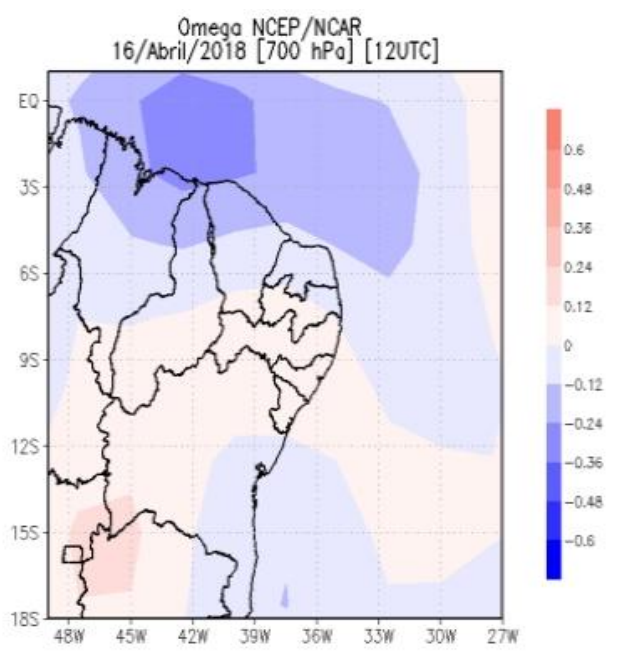



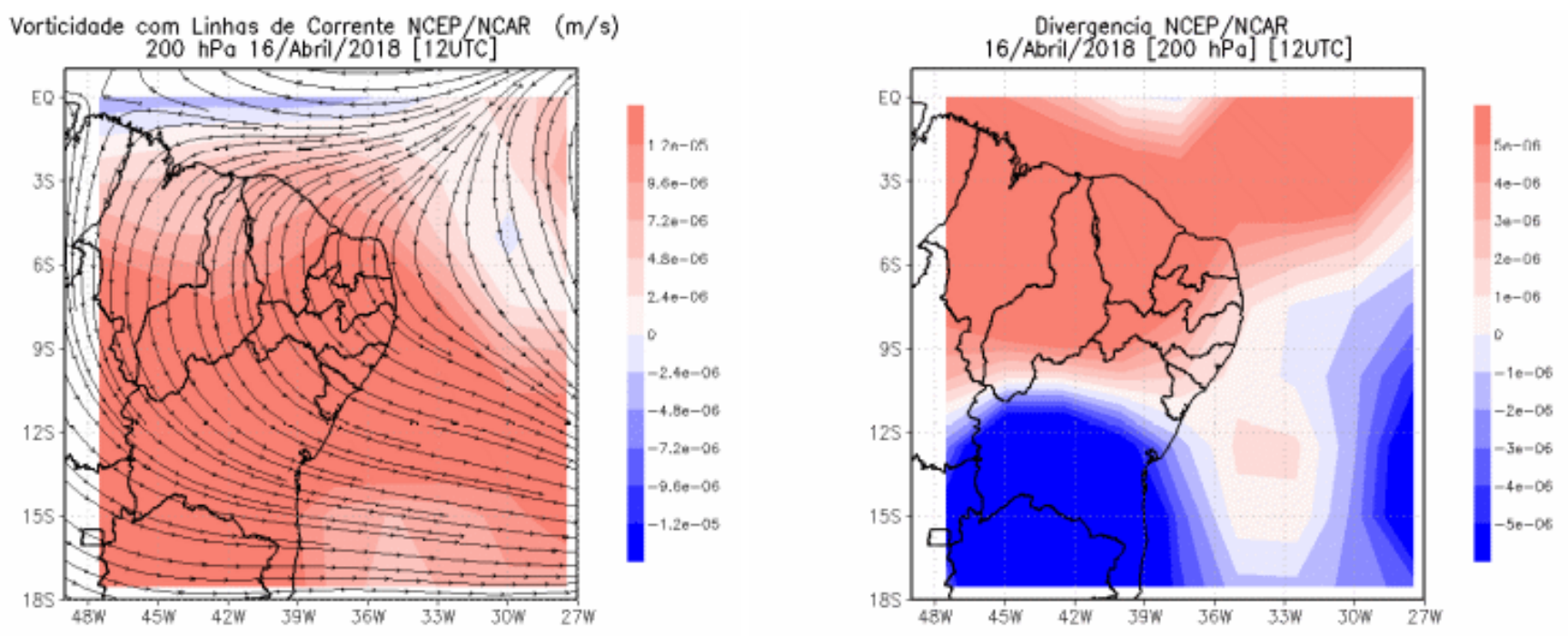

Figura 4 - Campos de vorticidade e linhas de corrente, ômega e divergência do vento, nos níveis de 850 (A), 700 (B) e 200 hPa (C), para o Ceará no dia 16/04/2018. Fonte: NCEP/NCAR. 


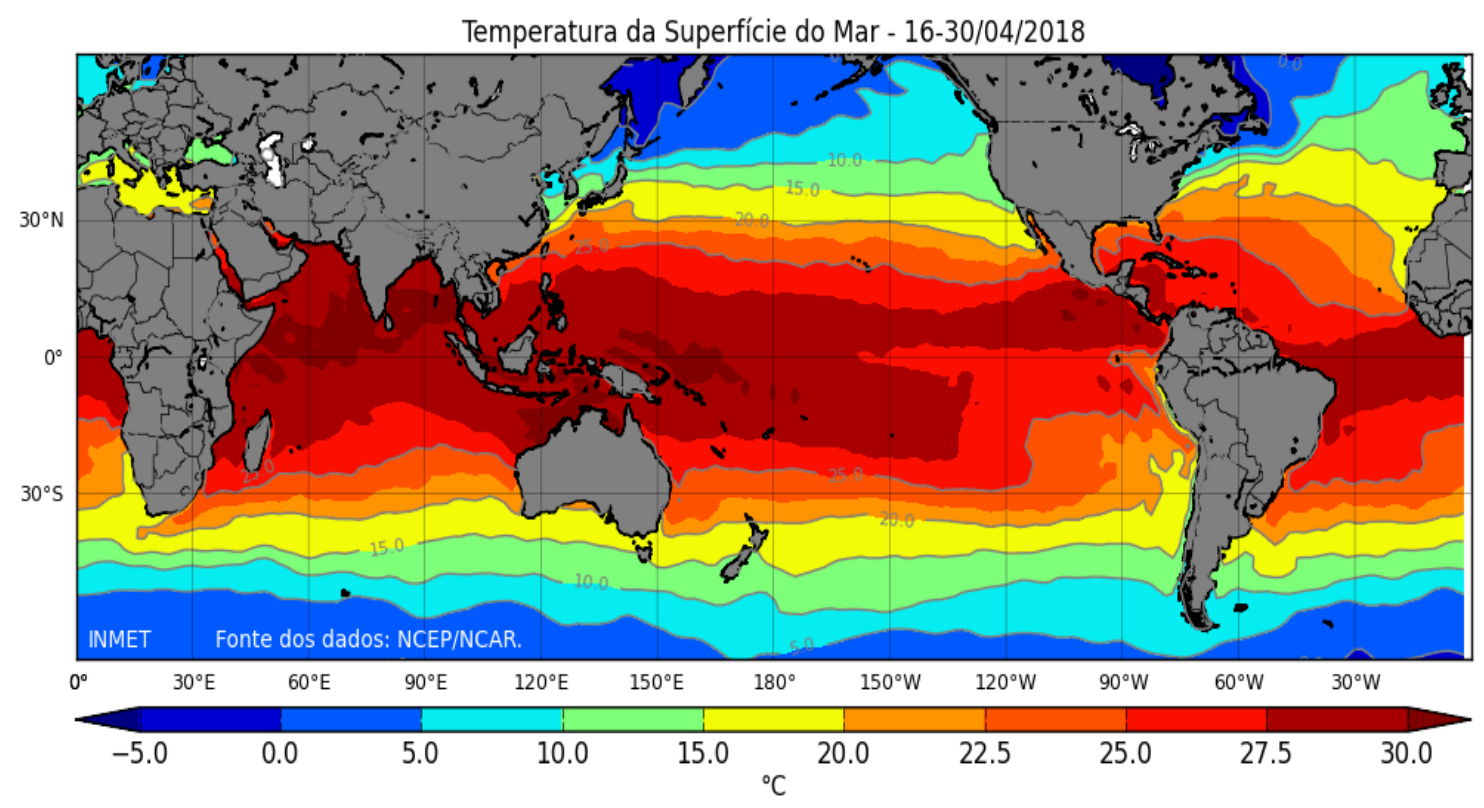

Figura 5 - Temperatura da Superfície do Mar-TSM quinzenal (de 16 a 30/04/2018). Fonte: INMET.

Segundo jornais de grande circulação, O Povo e o Diário do Nordeste, no dia 16 de abril de 2018, a cidade de Fortaleza, sofreu com graves consequências por causa do alto índice pluviométrico. A principal consequência deste evento foi devido aos alagamentos e transtornos em diversos bairros da capital, como Quintino Cunha e Antônio Bezerra como mostram as Figuras 6A e 6B. A água atingiu níveis preocupantes em alguns bairros da capital, invadindo casas, danificando móveis e levando lixo proveniente das ruas para o interior das residências, como pode ser observado na Rua Padre Manoel Primo, localizada no bairro Quintino Cunha (Figura 6). Ocorreram também explosões em virtude de danos em fios de alta-tensão. Moradores relataram que com os ventos fortes os fios balançavam e cada vez que se encostavam um no outro causavam pequenas explosões. Além de congestionamento no tráfego de veículos (Figura $6 C)$. 


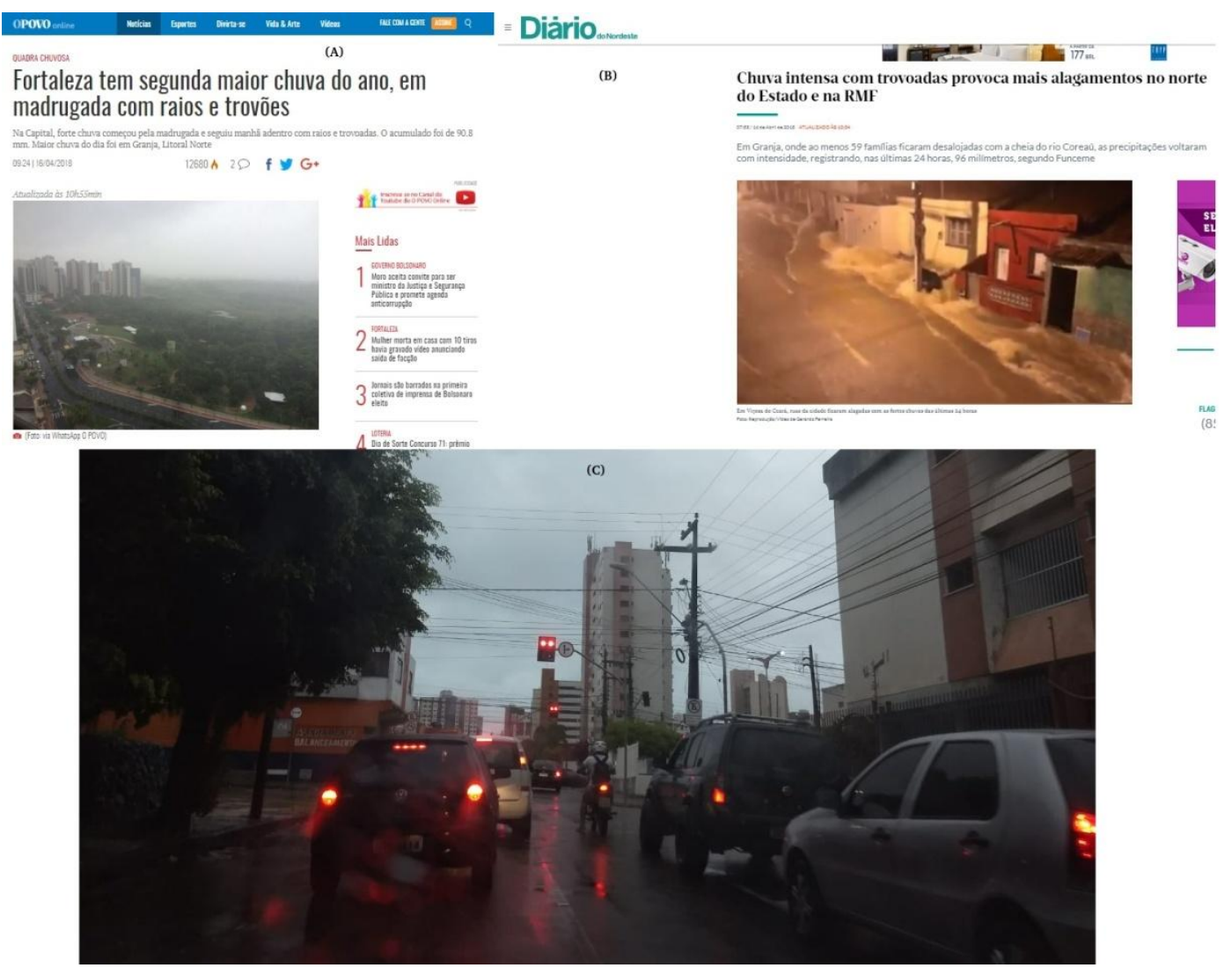

Figura 6 - Notícias e imagem da consequência da chuva no dia 16/04/2018. Fonte da imagem: Diário do Nordeste e O Povo.

\section{CONCLUSÕES}

As análises mostraram que, no dia 16/04/18, as 09h00min local (1200 UTC), período que o sistema se intensificou, foi observado um intenso movimento ascendente de ar na sua região de formação, acompanhado de convergência e incidência de forte circulação ciclônica na baixa troposfera. Esse núcleo fechado de vorticidade ciclônica provavelmente foi o responsável pela forma circular do SCM.

A formação do SCM teve influência direta da instabilidade associada às águas mais aquecidas próximo à costa norte NEB.

Este trabalho mostrou que o SCM que se propagou meridionalmente entre os estados da Paraíba e do Rio Grande do Norte, induziu grandes volumes de precipitação na cidade de Fortaleza, com acumulados diários em torno de 90 $\mathrm{mm}$, bem como influenciou significativamente as variáveis meteorológicas locais e ocasionou grandes transtornos tanto para a cidade como principalmente para a população urbana, interferindo sobremaneira nas suas atividades essenciais. 


\section{REFERÊNCIAS}

ALBUQUERQUE, C.S.M. Desenvolvimento e Trajetórias dos Complexos Convectivos de Mesoescala no Estado de Alagoas entre os anos de 1999 e 2009. Monografia (Trabalho de Conclusão de Curso em Meteorologia) Instituto de Ciências Atmosféricas, Curso de Graduação em Meteorologia, Universidade Federal de Alagoas, Maceió, 2011.

CONTI, J.B. Clima e Meio Ambiente. São Paulo: Atual Editora, 7a ed, p. 96, 2011.

CPTEC. Centro de Previsão de Tempo e Estudos Climáticos. Imagens de Satélite realçadas no espectro infravermelho no dia 16/04/2018. Disponível em: http//www.cptec.inpe.br/. Acesso em: 12 dez. 2018.

CHUVA intensa com trovoadas provoca mais alagamentos no norte do Estado e na RMF. Diário do Nordeste. Disponível em www.diariodonordeste.verdesmares.com.br. Acesso em 12 dez. 2018.

FUNCEME. Fundação Cearense de Meteorologia e Recursos Hídricos. Disponível em: www.funceme.br/app/calendario. Acesso em: 12 dez. 2018.

HASTENRATH, S.; HELLER, L. Dynamics of climatic hazards in Northeast Brazil. Quarterly Journal of the Royal Meteorological Society, London, v. 103, p. 77-92, 1977.

MOURA, A.D.; SHUKLA, J. On the dynamics os droughts in northeast Brazil: Observations, theory and numerical experiments with a general circulation model. Journal of the Atmospheric Science, Boston, v. 38, n. 7, p. 2653-2675, 1981.

MADDOX, R.A. Mesoescale convective complexes. Bull. Am. Meteorol. Soc., v. 53, p. $135-156.1980$.

MILHAHN JUNIOR, A.W. Correntes de Jato e Sistemas Associados aos Complexos Convectivos de Mesoescala no Nordeste Brasileiro. Monografia (Trabalho de Conclusão de Curso em Meteorologia)- Instituto de Ciências Atmosféricas, Curso de Graduação em Meteorologia, Universidade Federal de Alagoas, Maceió, 2013.

MONTEIRO, J.B.; ZANELLA, M.E. Eventos extremos diários em Fortaleza-CE, Brasil: Uma análise estatística de episódios pluviométricos intensos. In: $14^{\circ}$ Encontro de Geógrafos da América Latina, Peru-Lima, Anales del XIV Encuentro de Geógrados de América Latina, 2013.

FORTALEZA tem segunda maior chuva do ano, em madrugada com raios e trovões. O Povo online, Fortaleza, 16 abril 2018. Disponível em: www.opovo.com.br. Acesso em: 12 dez. 2018.

ROZANTE, J. R.; MOREIRA, D. S. ; GONÇALVES., L. G. G. ; VILA, DANIEL A . Combining TRMM and Surface Observations of Precipitation: Technique and Validation Over South America. Weather and Forecasting, v. 25, p. 885-894. 2010.

SOUZA, E. B., ALVES, J.M.B., REPELLI, C.A. Um complexo convectivo de mesoescala associado à precipitação intensa sobre Fortaleza-CE. Revista Brasileira de Meteorologia. v.13., n.2., p.1-14, 1998. 
SOUZA, E. P.; RENNÓ, N. O; SILVA DIAS, M. A. F. Convective circulations induced by surface heterogeneities. Journal of the Atmospheric Sciences, Boston, v. 57, n. 16. p. 2915-2922, 2000,

SILVA DIAS, M.A.da F.; ROZANTE, J.R.; MACHADO, L.AT. Complexos Convectivos de Mesoescala na América do Sul. Tempo e Clima do Brasil. Oficina de Texto. São Paulo. p.181-191. 2009.

SILVEIRA, M.H.S. Complexos Convectivos de Mesoescala no Estado de Alagoas. Monografia (Trabalho de Conclusão de Curso em Meteorologia) - Instituto de Ciências Atmosféricas, Curso de Graduação em Meteorologia, Universidade Federal em Alagoas, 2010.

VELASCO, I. FRITSH, J. M. Mesoscale Convective Complexes in the Americas. J. Geophys. Res., 92(D8): 9591-9613, 1987.

VILA, D.A.; MACHADO, L.A.T.; LAURENT, H.; VELASCO, I. Forecast and Tracking the Evolution of Cloud Clusters (ForTrACC) Using Satellite Infrared Imagery: Methodology and Validation. Weather and Forecasting, v. 23,p.233-245, 2008.

VILA, D. A.; DE GONCALVES, L. G. G.; TOLL, D. L.; ROZANTE, J. R. Statistical evaluation of combined daily gauge observations and and rainfall satellite estimates over continental South America. Journal Hydrometeorology, v.10, p.533-543, 2009.

WANG, C. Atlantic climate variability and its associated atmospheric circulation cells. Journal of Climate, v. 15, p. 1516-1536, 2002.

ZANELLA, M.E. Eventos pluviométricos intensos em ambiente urbano: Fortaleza, episódio do dia 29/01/2004. In: SILVA, José Borzachiello da; DANTAS, Eustógio Wanderley Correia; ZANELLA, Maria Elisa; MEIRELES, Antônio Jeovah de Andrade (Org.). Litoral e Sertão: natureza e sociedade no nordeste brasileiro. Fortaleza: Expresso Gráfica, p. 195-207, 2006. 